\title{
AVALIAÇÃO DO POTENCIAL USO DE BIOGLICERINA COMO BASE PARA FORMULAÇÃO DE FLUIDOS DE PERFURAÇÃO AQUOSOS PARA POÇOS DE PETRÓLEO E GÁS
}

\author{
Cleysson C. Corrêa ${ }^{a}$, Georgiana F. da Cruz ${ }^{a}$, Alexandre S. L. Vaz Jra, Bianca de S. A. Araújo ${ }^{a}$, Alexsandro A. da Silvab, \\ Rafael A. Rodrigues ${ }^{b}$, Rosana F. T. Lombac e Alex T. de A. Waldmann ${ }^{c}$ \\ áaboraório de Engenharia e Exploração de Petróleo, Universidade Estadual do Norte Fluminense Darcy Ribeiro, 27.925-535 \\ Macaé - RJ, Brasil \\ ${ }^{b}$ Central Analítica Fernanda Coutinho, Instituto de Química, Universidade do Estado do Rio de Janeiro, 20550-900 Rio de Janeiro \\ - RJ, Brasil \\ ${ }^{\mathrm{c} C e n t r o ~ d e ~ P e s q u i s a s ~ e ~ D e s e n v o l v i m e n t o ~ L e o p o l d o ~ A m e ́ r i c o ~ M i g u e z ~ d e ~ M e l l o, ~ C i d a d e ~ U n i v e r s i t a ́ r i a, ~ 21941-915 ~ R i o ~ d e ~ J a n e i r o ~}$ \\ - RJ, Brasil
}

Recebido em 17/08/2016; aceito em 26/12/2016; publicado na web em 14/02/2017

\begin{abstract}
USE POTENTIAL OF BIOGLYCERIN AS A BASIS FOR AQUEOUS DRILLING FLUIDS FORMULATION OF OIL AND GAS WELLS. The growing global concern about the environment associated with academic and government efforts are enabling a number of alternatives for sustainable development. Within this perspective one can include the search for value-added products using waste from renewable energy sources, such as those from the production of biodiesel. The rapid development of biodiesel production in Brazil directly affected the supply of glycerin and therefore the sector is seeking a market that can absorb this waste. Thus, with the increasing search for environmentally friendly products, formulation of a drilling fluid using a co-product of biodiesel production to replace the n-paraffin is of great importance to the oil industry for meeting the requirement of environmental regulation and, in addition, considerably reducing the cost of raw materials. In this context, the aim of this study was to characterize different glycerins to evaluate their potential as basis for drilling fluids for oil wells and gas. The glycerins were stable under the conditions evaluated without phase separation and precipitation of solids, exhibited good rheological profile and low value of interface tension. The results indicate a strong possibility of use of these glycerins as basis for drilling fluids and applicability by the oil industry.
\end{abstract}

Keywords: glycerin; drilling fluids; petroleum industry.

\section{INTRODUÇÃO}

Fluidos de perfuração para poços de petróleo e gás são dispersões complexas de sólidos, líquidos e/ou gases, usualmente constituídas de uma fase dispersante ou base (aquosa ou orgânica) e outra dispersa, cuja complexidade depende da natureza dos produtos dispersos, dos requisitos e das funções necessárias para operação de perfuração, tais como manutenção da integridade da parede do poço, remoção dos cascalhos gerados durante o processo de perfuração, resfriamento e lubrificação da coluna de perfuração e da broca. ${ }^{1}$ Dependendo da composição de sua fase dispersante, os fluidos de perfuração podem ser à base de água (Water-Based Drilling Fluids - WBDF), à base de gás (Gas-Based Drilling Fluids - GBDF) e à base de óleo (Oil-Based Drilling Fluids - $O B D F$ ), que inclui fluidos de base oleosa sintética (Synthetic-Oil-Based Drilling Fluids - SOBDF).

Desde o início da utilização de fluidos de perfuração, quando se utilizava a água para auxiliar as ferramentas na construção dos poços de água subterrânea, seu desenvolvimento permanece até hoje como um grande desafio para a indústria do petróleo, na busca por um fluido que seja de baixo custo, de fácil manipulação, com propriedades técnicas adequadas e ambientalmente correto. ${ }^{2}$ A indústria do petróleo investe permanentemente em pesquisa e desenvolvimento de novas tecnologias, tanto em produtos (aditivos) quanto em novas bases para sistemas de fluidos de perfuração, especialmente no Brasil, à medida que os poços de petróleo e gás se tornam mais profundos e novos cenários mais complexos vão surgindo, tais como os poços de petróleo perfurados no cenário do pré-sal e poços com geometria complexa envolvendo trechos de

*e-mail: geofec@gmail.com alta inclinação e horizontais de grande afastamento e atravessando diferentes tipos de formações rochosas.

Atualmente existe uma grande variedade de formulações de fluidos de perfuração principalmente de bases aquosa e oleosa. Essa variedade de formulações cresce à medida que aumenta a complexidade na perfuração de poços de petróleo e para evitar problemas relacionados com a inibição na hidratação de folhelhos reativos, a lubricidade em fases com ganho de ângulo, a perfuração de formações salinas, a perda de fluido, os danos causados por efeito capilar em reservatórios de baixa permeabilidade, a invasão de fluidos da formação para o poço, dentre outros.

Os fluidos à base de água (salgada, doce ou salmoura) não-inibidos são os mais comumente utilizados especialmente nas fases iniciais da perfuração, em que as rochas são praticamente inertes. ${ }^{3,4}$ Quando a perfuração é realizada em rochas de elevado grau de reatividade na presença de água, é recomendável a utilização dos fluidos aquosos contendo eletrólitos e/ou polímeros que diminuem ou retardam esta reatividade (fluidos inibidos). E, no caso de perfurações especiais como, por exemplo, para aumentar a taxa de penetração da broca e/ ou com o objetivo de reduzir a densidade do sistema, recomenda-se o uso dos fluidos aquosos com baixo teor de sólidos e os emulsionados com óleo. ${ }^{4}$

Por outro lado, os fluidos à base de óleo (óleo diesel ou óleo mineral com até $2 \%$ de água ou os de emulsão inversa com até $50 \%$ de água) são desenvolvidos para perfuração de formações com folhelhos altamente reativos ou de poços sujeitos a altas pressões e temperaturas ou, ainda, de poços direcionais e que necessitem de uma maior lubrificação entre a coluna e as formações rochosas. ${ }^{5,6}$ No entanto, apesar de apresentarem melhores performances que os fluidos aquosos, os fluidos oleosos apresentam custo elevado e elevada toxicidade..$^{7-11}$ 
Como uma alternativa às limitações de desempenho dos fluidos aquosos e para suprir às restrições ambientais impostas aos fluidos à base de óleo convencionais, surgiram os fluidos oleosos sintéticos de base orgânica, os quais utilizam como fase dispersante parafinas lineares, ésteres, éteres, alquilbenzenos lineares (LABs), olefinas internas (IO’s), olefinas alfa-lineares (LAO), poli-alfa olefinas (PAO), acetais e glicóis. ${ }^{12}$ No entanto, mesmo esses fluidos sendo menos tóxicos e mais biodegradáveis que os de base oleosa convencional, é necessário considerar as restrições impostas pelos órgãos ambientais com relação ao descarte de fluidos e cascalhos gerados durante a perfuração no mar. No Brasil, por exemplo, atualmente o fluido de perfuração não aquoso deve apresentar teor de hidrocarbonetos poliaromáticos menor que $10 \mathrm{ppm}$ e os cascalhos gerados não podem apresentar mais de 6,9\% (em peso úmido de cascalho) de base orgânica tipo parafinas lineares ou óleo mineral tratados e 9,4\% (em peso úmido de cascalho) no caso da base orgânica ser de IO's, LAO, PAO, ésteres, éteres e acetais. ${ }^{13}$

Este novo e desafiador contexto coloca os pesquisadores na busca de um fluido que possua desempenho semelhante aos fluidos oleosos sintéticos, de baixo custo e que atenda aos requisitos ambientais exigidos por lei, como os fluidos de base aquosa. Assim, na busca de uma nova base para o desenvolvimento de tal fluido e impulsionados pelo aumento progressivo da utilização de biodiesel na formulação do diesel comercial, ${ }^{14}$ decidiu-se testar a glicerina bruta proveniente da produção de biodiesel (aqui denominada de bioglicerina), que é menos tóxica e mais biodegradável que a maior parte das bases oleosas sintéticas atualmente utilizadas, além de ser considerada uma matéria-prima abundante e de baixo custo no país. Adicionalmente, a bioglicerina apresenta em sua composição o glicerol, que é um composto orgânico solúvel em água, com baixa tensão interfacial, baixa condutividade e maior densidade quando comparada com a água. Estas características propiciam menor adição de sólidos, responsáveis pelo aumento do peso do fluido, assim como evita a solubilidade de sais e o inchamento de argilas assemelhando-se com as bases sintéticas mais empregadas na formulação de fluidos, parafina e olefina. ${ }^{15}$

\section{Glicerina}

A glicerina, também denominada de glicerol (componente químico puro) ou propan-1,2,3-triol, pode ser obtida, com maior grau de pureza e maior quantidade de glicerol, a partir do processo de obtenção do sabão mediante reação de saponificação de triglicerídeos com hidróxido de sódio ou potássio, como também por meio da reação de hidrólise para obtenção de ácidos graxos. Além disso, pode-se obtê-la a partir do processo de transesterificação para produção de biodiesel, com menor grau de pureza, porcentagem de glicerol em torno de 65 a $70 \%(\mathrm{p} / \mathrm{p})$ e aproximadamente $30 \%$ de impurezas como sabão, resíduos de metanol ou etanol, hidróxido de sódio, ácidos graxos livres, mono e diacilglicerol, ésteres, oligômeros de glicerol, MONG (matéria orgânica não-glicerol), polímeros e água. ${ }^{16-19}$

O rápido desenvolvimento da produção de biodiesel no Brasil, impulsionado pelo incremento progressivo de sua participação na composição do diesel comercial (atualmente a proporção é de 93:7 de diesel:biodiesel), afetou diretamente a oferta de bioglicerina no mercado e, por isso, o setor de biodiesel busca um mercado para absorver essa bioglicerina produzida no processo industrial. Boa parte da bioglicerina gerada nas plantas de biodiesel é queimada em fornos e caldeiras para geração de energia calorífica em unidades industriais e, apesar desta atividade ser uma alternativa ambientalmente correta, porque a bioglicerina substitui a lenha e combustíveis fósseis, como óleo combustível e carvão, ela não gera nenhum produto com alto valor agregado. ${ }^{20}$ Associado a isso, a grande oferta no mercado e o baixo grau de pureza da bioglicerina também contribuem para seu baixo custo, em torno de $\mathrm{R} \$ 0,20$ a 0,40 por $\mathrm{kg}$, o que favorece a possibilidade de uma gama de aplicações dessa matéria-prima pela indústria. ${ }^{19}$ Além das aplicações já utilizadas pelas indústrias de cosméticos, alimentícias e farmacêuticas ou na obtenção de substâncias químicas com alto valor agregado, vários pesquisadores têm se dedicado a utilizá-la das mais diversas maneiras, tais como em processos de recuperação secundária de petróleo, ${ }^{21}$ na produção de biogás ${ }^{22}$ e, mais recentemente, na área de fluidos ambientalmente corretos para a indústria do petróleo ${ }^{23-26}$ como aditivo para fluidos base água, ${ }^{27-29}$ com a função de aumentar a viscosidade do fluido a baixas taxas de cisalhamento. No entanto, poucos trabalhos na literatura citam o uso da bioglicerina como base para formular fluidos de perfuração, ${ }^{25,26,30,31}$ o que justifica a escolha do tema proposto neste trabalho.

O uso da bioglicerina como base para fluidos de perfuração de poços de petróleo seria, portanto, uma alternativa viável, não só devido às suas carcterísticas, mas também ao alto valor que seria agregado a este resíduo que seria descartado. Neste âmbito, o objetivo deste artigo é fazer um estudo das características químicas, das estabilidades térmica e oxidativa, da salinidade, da tensão interfacial, da inibição de inchamento de argila e dos parâmetros reológicos de diferentes bioglicerinas para avaliar seu potencial uso como base para formulação de fluidos de perfuração aquoso para poços de petróleo e gás, atendendo às exigências da indústria do petróleo com foco especial no Brasil.

\section{PARTE EXPERIMENTAL}

Os procedimentos laboratoriais utilizados neste trabalho, com exceção das análises de caracterização química, foram baseados nas normas API para fluido aquoso API RP 13B-1 (2009). ${ }^{32}$ Vale ressaltar que não existem normas API ou outras para qualificar uma base para fluidos de perfuração de poços de petróleo e gás e, por isso, resolveu-se testar várias técnicas de caracterização para glicerinas de diferentes características e origens com o intuito de estabelecer um protocolo padrão para caracterização desta matéria-prima como base para formulação destes fluidos.

\section{Amostras de glicerinas}

Foram avaliadas amostras de bioglicerinas provenientes de diferentes processos de produção de biodiesel e de várias fontes como soja, sebo, misturas soja:sebo fornecidas pela empresa Fuga Couros S/A (BIOFUGA/RS) com as seguintes proporções: $100 \%$ soja (Lote A), 100\% sebo (Lote B), 70:30 soja:sebo (Lote C), 60:40 sebo:soja (Lote E). Utilizou-se também uma bioglicerina de óleo residual fornecida pela empresa Biotechnos (Lote D), uma amostra de glicerina purificada comercial fornecida pela empresa Oxiteno (Lote F), duas amostras fornecidas pela Petrobras denominadas bioglicerina loira A (Lote G) e loira B (Lote I), ambas $100 \%$ soja e, por fim, outra bioglicerina $100 \%$ soja fornecida pela Cargil (Lote H). Em alguns desses lotes as bioglicerinas foram entregues com laudos técnicos informando o teor de glicerol, umidade, MONG, $\mathrm{pH}$ e densidade, como mostra a Tabela 1 .

\section{Caracterização química por CG/DIC, CG/EMIT e RMN ${ }^{1} \mathrm{H}$}

Foram realizadas análises de cromatografia gasosa acoplada a detector por inonização em chama (CG/DIC), cromatografia gasosa acoplada a espectrometria de massas ion-trap (CG/EMIT) e ressonância magnética nuclear de hidrogênio $\left(\mathrm{RMN}^{1} \mathrm{H}\right)$, com o intutito de confirmar a presença do glicerol e verificar a presença de impurezas inerentes ao processo de obtenção do biodiesel.

As análises por CG/DIC foram realizadas em um cromatógrafo em fase gasosa da Bruker Daltonics Inc 456-GC Scion, com detector 
Tabela 1. Glicerinas avaliadas e algumas de suas propriedades químicas e físicas

\begin{tabular}{|c|c|c|c|c|c|c|c|}
\hline \multirow{2}{*}{ Glicerina } & \multirow{2}{*}{ Matéria-prima } & \multicolumn{6}{|c|}{ Propriedades físicas e químicas avaliadas ${ }^{\mathrm{a}}$} \\
\hline & & Grau de pureza $(\%)^{\mathrm{b}}$ & Umidade (\%) & $\operatorname{MONG}^{\mathrm{c}}(\%)$ & Cloretos (ppm) & $\mathrm{pH}$ & $\mathrm{D}^{\mathrm{d}}(\mathrm{g} / \mathrm{mL})$ \\
\hline Lote $\mathrm{A}^{\mathrm{e}, \mathrm{f}}$ & Soja & 84,83 & 8,53 & 3,75 & 31900 & 5,95 & 1,24 \\
\hline Lote $B^{\mathrm{f}}$ & Sebo & 84,83 & 8,53 & 3,75 & 31900 & 5,95 & 1,24 \\
\hline Lote $\mathrm{C}^{\mathrm{f}}$ & Soja:sebo $(70: 30)$ & 84,83 & 8,53 & 3,75 & 31900 & 5,95 & 1,24 \\
\hline Lote $\mathrm{E}^{\mathrm{f}}$ & Sebo:soja (60:40) & 84,83 & 8,53 & 3,75 & 31900 & 5,95 & 1,24 \\
\hline Lote $\mathrm{F}^{\mathrm{g}}$ & $\mathrm{NI}^{\mathrm{h}}$ & $99,70-100$ & $0,0-0,30$ & 0,30 & 10 & 5,5 & 1,26 \\
\hline Lote $\mathrm{G}^{\mathrm{e}}$ & Soja & 69,20 & 21,70 & NI & NI & $\mathrm{NI}$ & NI \\
\hline Lote $\mathrm{H}^{\mathrm{e}}$ & Soja & 84,09 & 11,52 & 0,70 & 36600 & 6,23 & NI \\
\hline Lote $\mathrm{I}^{\mathrm{e}}$ & Soja & 72,90 & 17,40 & NI & 32400 & NI & NI \\
\hline
\end{tabular}

aPropriedades fornecidas pelas empresas que doaram as bioglicerinas por meio de laudos técnicos; ${ }^{\mathrm{b}}$ grau de pureza baseado no teor de glicerol; ${ }^{\mathrm{c}} \mathrm{MONG}=\mathrm{matéria}$ orgânica não-glicerol; ${ }^{\mathrm{d}} \mathrm{D}=$ Densidade; ${ }^{\mathrm{e} B i o g l i c e r i n a s ~ d e ~ m e s m a ~ m a t e ́ r i a-p r i m a, ~ p o r e ́ m ~ f o r n e c i d a s ~ p o r ~ d i f e r e n t e s ~ e m p r e s a s ; ~}{ }^{\mathrm{F}} \mathrm{Mesmo}$ grau de pureza, coloração diferente, lote A (2,89\% de cinzas, $3,94 \%$ de voláteis, $0,012 \%$ de metanol), lote B (2,95\% de cinzas, $3,14 \%$ de voláteis, $0,010 \%$ de metanol), lotes C e E ( $3,15 \%$ de cinzas, $2,94 \%$ de voláteis, $0,008 \%$ de metanol); ${ }^{g}$ glicerina pura vegetal grau USP ou farmacêutico; ${ }^{\mathrm{h}} \mathrm{NI}=\mathrm{Não}$ informado.

do tipo ionização por chama. Foi utilizado uma coluna capilar de sílica fundida BR-5MS (30 m x 0,25 mm x 0,25 $\mu \mathrm{m} ; 5 \%$ fenil, $95 \%$ metilpolisiloxano). O gás de arraste foi o hidrogênio com fluxo constante de $1,0 \mathrm{~mL} \mathrm{~min}^{-1}$. A temperatura do injetor foi de $180{ }^{\circ} \mathrm{C}$ e a programação de temperatura foi $80^{\circ} \mathrm{C}(0 \mathrm{~min})$ até $150{ }^{\circ} \mathrm{C}$ à $4{ }^{\circ} \mathrm{C}$ $\mathrm{min}^{-1}$, totalizando 17,50 minutos de análise. $\mathrm{O}$ volume injetado foi de $1 \mu \mathrm{L}$ da amostra diluída em metanol na concentração de $0,1 \mathrm{mg}$ $\mathrm{mL}^{-1}$, no modo de injeção Split 1:20. Os resultados obtidos foram processados pelo software de dados Galaxie 1.10.

As análises por CG/EMIT foram realizadas em um cromatógrafo a gás Varian Inc. GC-3900 acoplado a espectrômetro de massas ion-trap Varian Inc. Saturn 2100 equipado com uma coluna VF-17MS (30 m x 0,25 mm x $0.25 \mu \mathrm{m}, 50 \%$ fenil, $50 \%$ metilpolisiloxano). O

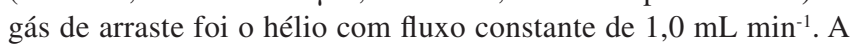
temperatura do injetor e a rampa de aquecimento foram as mesmas utilizadas na análise por CG/DIC. A temperatura do trap foi $150^{\circ} \mathrm{C}$, do manifold $40^{\circ} \mathrm{C}$ e da linha de transferência $220^{\circ} \mathrm{C}$. Fonte de íons de $70 \mathrm{eV}$ com filamento on em 3 minutos e uma faixa de massas de 30 a 300 Da. O preparo da amostra e o modo de injeção também foram os mesmos utilizados na análise por CG/DIC e utilizou-se um padrão de glicerina P.A. da Hexis com teor mínimo de 99,5\%. Os resultados obtidos foram processados pelo sistema de dados MS Workstation.

As análises por $\mathrm{RMN}^{1} \mathrm{H}$ foram realizadas em equipamento Varian Gemini de $600 \mathrm{MHz}$ utilizando tubos de RMN apropriados. Água deuterada foi utilizada como solvente, tetrametilsilano como padrão interno de referência e os deslocamentos químicos foram expressos em ppm.

\section{Análise de reologia}

Esta análise foi realizada para medir a viscosidade das bioglicerinas quando submetidas a diferentes forças cisalhantes. Para isso, calculou-se o limite de escoamento (LE), a viscosidade plástica (VP) e a sua capacidade em formar um gel (medida das forças géis inicial, $\mathrm{G}_{\mathrm{i}}$ e final, $\mathrm{G}_{\mathrm{f}}$ ). Todas as medidas foram realizadas em viscosímetro Fann 35A com diferentes forças cisalhantes (L600, L300, L200, L100, L6 e L3), seguindo a norma API RP $13 B-1^{32}$ a $120^{\circ} \mathrm{F}\left(49^{\circ} \mathrm{C}\right)$ antes e após o envelhecimento (para simular condições extremas de temperatura semelhantes às que o fluido é submetido em operações reais de perfuração de poços de petróleo e gás) das diferentes glicerinas por $16 \mathrm{~h}$ a $200{ }^{\circ} \mathrm{F}\left(93^{\circ} \mathrm{C}\right)$ em forno rotativo e com $\mathrm{pH}$ entre 9 - 10. Este equipamento é o mesmo utilizado como padrão para fluidos de perfuração de poços de petróleo e gás, a diferentes forças cisalhantes (L600, L300, L200, L100, L6 e L3). A VP foi determinada subtraindo-se da leitura a $600 \mathrm{rpm}$ (L600) a leitura a $300 \mathrm{rpm}$ (L300) e o valor foi expresso em Centipoise (cP). O LE foi obtido subtraindo-se a leitura a $300 \mathrm{rpm}$ do resultado da VP e foi expresso em lbf / $100 \mathrm{ft}^{2} . \mathrm{O} \mathrm{G}_{\mathrm{i}}$ e $\mathrm{G}_{\mathrm{f}}$ foram obtidos a partir das leituras L3 e L600 e o valor também foi expresso em lbf / $100 \mathrm{ft}^{2}$.

\section{Salinidade}

O teor de cloreto nas amostras de bioglicerinas estudadas (com exceção da bioglicerina lote D) foi determinado utilizando-se o método padrão API RP 13B-1, ${ }^{32}$ em que o íon cloreto é precipitado sob a forma de $\mathrm{AgCl}$, por meio da titulação com adição equimolar (em relação à quantidade de cloretos) de $\mathrm{AgNO}_{3}$ (método de Mohr). Anotou-se o volume gasto, em $\mathrm{mL}$, da solução de $\mathrm{AgNO}_{3}$ e calculou-se o teor de cloretos $\left(\mathrm{mg} \mathrm{L}^{-1}\right)$.

\section{Teste de inchamento de argila (folhelho)}

O ensaio utilizado neste caso foi o de deformação linear para medir o grau de inchamento da argila em contato com as bioglicerinas por meio do equipamento Fann Instrument, Company Linear Swell Meter (LSM), modelo 2000 conforme norma API RP 13B-132 utilizando a bentonita como argila padrão. As pastilhas de bentonita necessárias para o teste foram confeccionadas utilizando-se $20 \mathrm{~g}$ da argila, prensadas a 10.000 psi. Os ensaios foram realizados com água industrial e com as bioglicerinas dos lotes C, E, F, I e H misturadas com água na proprorção 50:50 v/v. Além disso, testou-se a eficiência do $\mathrm{KCl}$ e de uma solução catiônica livre de cloreto como inibidores de inchamento de argila. As medidas de deformação foram realizadas por meio de um transdutor automático-digital que permitiu sua leitura direta. O tempo total de ensaio foi de $12 \mathrm{~h}$ e os dados obtidos foram tratados pelo Software do equipamento, LSM 2000.

\section{Medida de tensão interfacial}

As medidas de tensão interfacial foram realizadas à temperatura de $23{ }^{\circ} \mathrm{C}$ para a água industrial, para as bioglicerinas dos lotes $\mathrm{B}, \mathrm{C}$, E e F e para a mistura dessas bioglicerinas com água nas proporções de 50:50 e 30:70 v/v de água:bioglicerina, utilizando o tensiômetro K6 da Krüss, que tem como princípio o Método do Anel de Du Nouy. 


\section{Análise termogravimétrica (TGA/DTG)}

As análises TGA, utilizadas para determinar a temperatura referente a perda de massa devida à vaporização do glicerol, foram realizadas em um analisador Termogravimétrico (TGA) - Q-50 da TA Instruments com programação de temperatura de 50 a $300{ }^{\circ} \mathrm{C}$, utilizando duas rampas de aquecimento independentes, uma de 10 ${ }^{\circ} \mathrm{C} \min ^{-1}$ e outra de $20{ }^{\circ} \mathrm{C} \mathrm{min}^{-1}$, para avaliar a estabilidade térmica em diferentes temperaturas. Utilizou-se $\mathrm{N}_{2}$ a $100 \mathrm{~mL} \mathrm{~min}^{-1}$. Foram analisadas cerca de 3-4 mg das bioglicerinas sendo que para a bioglicerina do lote $\mathrm{C}$ acrescentou-se 10, 20, 30 e 50\% de água para avaliar a estabilidade térmica em misturas com água. As curvas termogravimétricas derivadas (DTG) foram obtidas pelo software do equipamento.

\section{Estabilidade oxidativa}

As análises de estabilidade oxidativa foram realizadas em um equipamento Rancimat 873 Biodiesel (Metrohm). Foram pesadas 3 $\mathrm{g}$ de cada bioglicerina em tubos de ensaio próprios do equipamento, os quais foram acomodados nos vasos de reação do Rancimat a temperatura de $93{ }^{\circ} \mathrm{C}$ sob fluxo de ar de $10 \mathrm{~L} \mathrm{~h}^{-1}$. Os produtos de oxidação voláteis gerados durante a análise foram transportados pelo fluxo de ar para outro recipiente contendo água destilada e a presença desses compostos foi detectada pelo aumento da condutividade no sistema. Ao final da análise registrou-se o tempo de indução (tempo decorrente até a detecção dos compostos voláteis, quando a amostra começa a degradar). ${ }^{33}$

\section{Cloud Point Temperature (CTP)}

Esta análise foi realizada com base no método de referência ASTM D 97 para testar a miscibilidade da mistura glicerina:água. Para isto utilizou-se as bioglicerinas puras e misturadas com água nas proporções 90:10, 70:30 e 50:50 v/v de bioglicerina:água. Dietilenoglicol puro e misturado com água nas mesma proporções testadas para as bioglicerinas foi utilizado como padrão. $\mathrm{O}$ teste foi realizado com as amostras $(3 \mathrm{~mL})$ acondicionadas em tubos de ensaios a 50,70, 100 e $130{ }^{\circ} \mathrm{C}$. A temperatura foi monitorada até o aparecimento da separação das fases.

\section{RESULTADOS E DISCUSSÃO}

\section{Caracterização e seleção das bioglicerinas por CG/DIC, CG/ EMIT e RMN ${ }^{1} \mathbf{H}$}

Sugere-se neste trabalho que as propriedades das bases que serão utilizadas na formulação de fluidos de perfuração aquosos para poços de petróleo e gás sejam adequadas às normas API RP 13B- ${ }^{32}$ aplicadas aos fluidos aquosos e que, além disso, sejam estáveis durante todo o processo de perfuração para que se tenha segurança operacional. Assim, considera-se importante que a matéria-prima que será utilizada como base seja previamente caracterizada para sua adequada seleção.

Devido à grande disponibilidade de diferentes tipos de bioglicerina no mercado brasileiro, considera-se que o grande desafio para a indústria do petróleo é poder formular fluidos de perfuração aquosos com qualquer tipo de bioglicerina como base, independente do processo e da fonte oleaginosa que a gerou. Baseado nisto, conforme mostrado na Tabela 1, selecionou-se glicerinas com diferentes características físicas e químicas, sendo possível classificá-las como: glicerina bruta de média pureza (80 - 90\% de glicerol) - lotes A, B, C, E e $\mathrm{H}$ - glicerina loira de baixa pureza (50 - 70\% de glicerol) - lotes G e I - e glicerina pura $(99,7$ - $100 \%$ glicerol $)$ - lote F.
As bioglicerinas foram inicialmente analisadas por meio de RMN ${ }^{1} \mathrm{H}$, CG/DIC e CG/EMIT, com o intuito de confirmar a presença do glicerol, bem como verificar a presença de impurezas que pudessem ser utilizadas para diferenciá-las. Pela análise dos espectros de RMN ${ }^{1} \mathrm{H}$ (Figura 1S) observou-se em todas as bioglicerinas sinais na forma de multipletos na região de 3,5 ppm característicos dos prótons metilênicos do grupo $\mathrm{CH}_{2} \mathrm{OH}$ do glicerol. $\mathrm{O}$ espectro de $\mathrm{RMN}{ }^{1} \mathrm{H}$ das bioglicerinas lotes A, B, C, E e F não mostraram a presença de picos característicos de possíveis impurezas, ao contrário da bioglicerina lote D que apresentou picos na região de 2-0,5 ppm e em 5,0 ppm, que pode ser indicativo destas impurezas, semelhante ao mostrado por Marbun et al. . $^{31}$

Os métodos de referência ASTM D 6751 e EN 142214 apontam que a técnica de CG/DIC é adequada para análise de glicerol livre em amostras de biodiesel e, por isso, também optou-se por esta técnica para complementar a caracterização das bioglicerinas avaliadas neste trabalho. Assim, a presença do glicerol também foi confirmada por meio das análises de CG/DIC e CG/EMIT. No método utilizado não foi possível observar a presença de impurezas nem mesmo na bioglicerina lote $\mathrm{D}$, e todas as bioglicerinas analisadas apresentou um único pico com tempo de retenção de 3,5 minutos na análise por CG/DIC e 4,4 minutos por CG/EMIT referente ao glicerol, confirmado pela injeção do padrão P.A. A Figura 1 mostra os cromatogramas obtidos por CG/DIC e CG/EMIT para a bioglicerina do lote $\mathrm{C}$ e a Figura $2 \mathrm{~S}$ para as demais amostras.

\section{Análises térmicas (TGA/DTG e CTP) e estabilidade oxidativa das bioglicerinas}

A análise termogravimétrica foi utilizada para determinar a temperatura referente a perda de massa devida à vaporização do glicerol, a temperatura de início de degradação térmica, a temperatura máxima de degradação e a porcentagem de perda de massa das bioglicerinas avaliadas nas duas taxas de aquecimento $\left(10\right.$ e $\left.20^{\circ} \mathrm{C} \mathrm{min}^{-1}\right)$. A determinação da temperatura máxima de degradação foi feita com base na $1^{\text {a }}$ derivada (DTG)

A perda de massa devido à vaporização de algum componente presente na mistura com a bioglicerina iniciou-se em torno de 120 ${ }^{\circ} \mathrm{C}$ para todas as bioglicerinas avaliadas, independentemente da taxa de aquecimento, semelhante ao observado por Castelló et al., ${ }^{34}$ que utilizaram 10-20 mg de glicerina P.A. Além disso, observou-se que a degradação térmica das bioglicerinas ocorreu em um único evento de perda de massa envolvendo apenas um passo de degradação. A Tabela 2 apresenta os valores obtidos a partir das curvas TGA/DTG (Figura 3S) para as temperaturas de início de degradação (Ti), temperaturas máximas de degradação (Tmáx), percentual de perda de massa e de resíduo gerado no final do processo, o qual pode estar relacionado a formação de novos produtos de polimerização, oxidação ou outros ${ }^{20}$ para as bioglicerinas lotes A, B e C. Em condições de temperatura de 349-475 ${ }^{\circ} \mathrm{C}$, Bühler et al. ${ }^{21}$ observaram a degradação da glicerina, com conversões entre 0,4 e $31 \%$, gerando metanol, acetaldeído, propionaldeído, acroleína, álcool alílico, etanol, formaldeído, $\mathrm{CO}, \mathrm{CO}_{2}$, e $\mathrm{H}_{2}$.

Observa-se na Tabela 2 que os picos máximos das curvas obtidas para as bioglicerinas avaliadas com taxa de aquecimento de $20{ }^{\circ} \mathrm{C}$ $\min ^{-1}$ são deslocados para uma temperatura maior quando comparado às curvas obtidas com taxa de aquecimento menor $\left(10^{\circ} \mathrm{C} \min ^{-1}\right)$. No entanto, não se observou uma relação direta da perda de massa com o aumento da taxa de aquecimento como citado por Castelló et al. ${ }^{34}$ os quais mostraram que para glicerina P.A. os efeitos térmicos e mássicos são mais intensos quanto maior é a taxa de aquecimento. Vale ressaltar que, segundo os fornecedores, estas bioglicerinas possuem diferentes porcentagens de voláteis, metanol, cinzas e/ou outras impurezas (Tabela 1) e isso pode ter influenciado as temperaturas de 


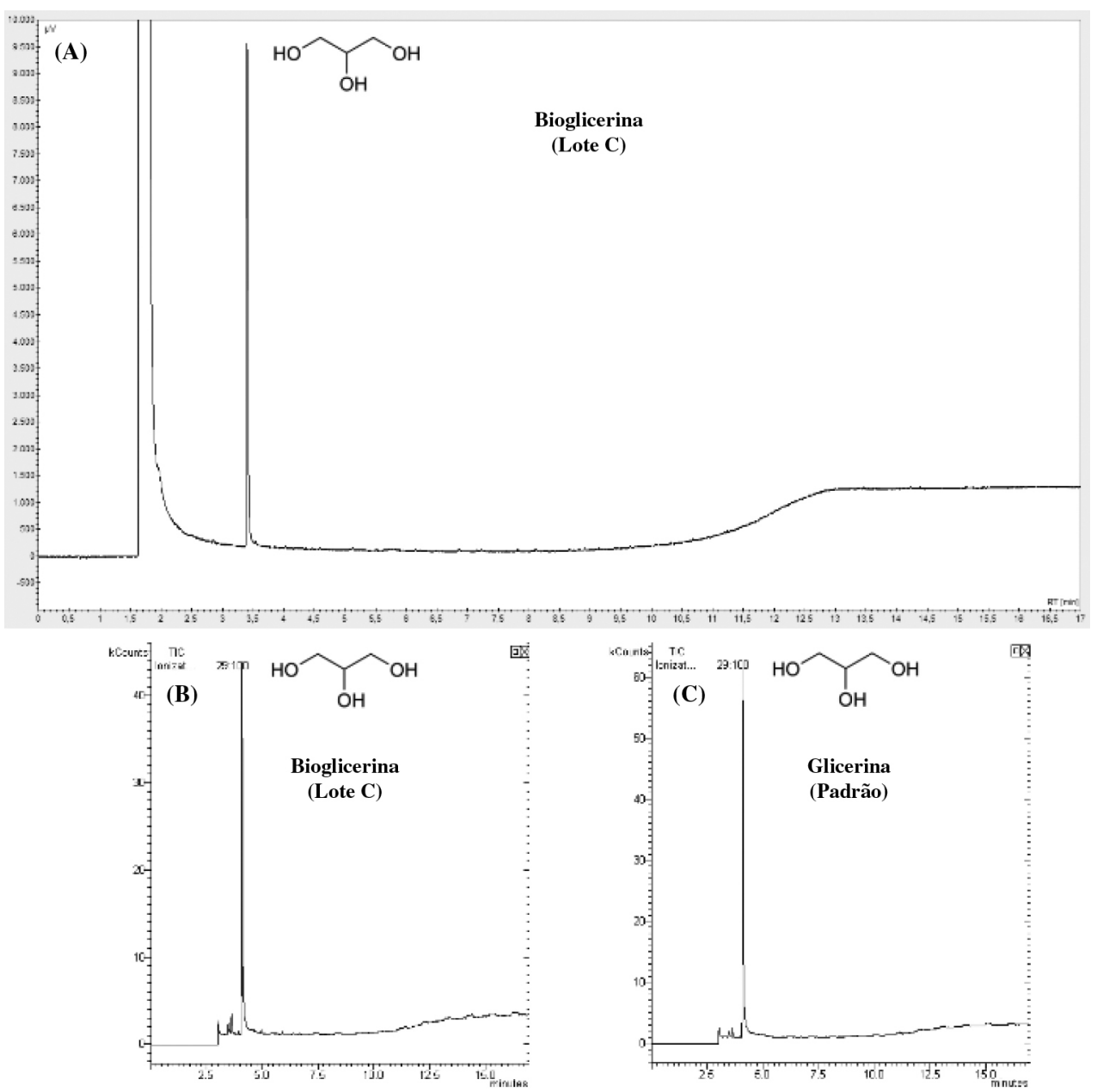

Figura 1. (A) Cromatograma da bioglicerina lote C obtido por CG/DIC; (B) Cromatograma da corrente total de íons da bioglicerina lote C obtido por CG/EMIT e (C) Cromatograma da corrente total de ions da glicerina P.A utilizada como padrão obtida por CG/EMIT

Tabela 2. Temperatura de início de degradação (Ti), temperatura máxima de degradação (Tmáx), percentual de perda de massa e de resíduo obtidos a partir das curvas de TGA/DTG para as bioglicerinas lotes A, B e C

\begin{tabular}{lccccc}
\hline \multirow{2}{*}{ Bioglicerinas } & $\begin{array}{c}\text { Taxa de aquecimento } \\
\left({ }^{\circ} \mathrm{C} \text { min }^{-1}\right)\end{array}$ & $\operatorname{Ti~}\left({ }^{\circ} \mathrm{C}\right)$ & Tmáx $\left({ }^{\circ} \mathrm{C}\right)$ & Perda de massa $(\%)$ & Resíduo $(\%)$ \\
\cline { 3 - 6 } Lote A & 10 & 161,73 & 184,08 & 87,73 & 5,26 \\
& 20 & 177,79 & 208,06 & 94,39 & 5,55 \\
Lote B & 10 & 168,57 & 192,65 & 90,99 & 7,01 \\
& 20 & 188,74 & 220,54 & 89,40 & 9,01 \\
Lote C & 10 & 173,72 & 199,83 & 88,84 & 10,60 \\
& 20 & 191,95 & 218,70 & & 11,16 \\
\hline
\end{tabular}

degradação obtidas a partir das curvas de TGA/DTG mesmo elas possuindo o mesmo grau de pureza.

Com o intuito de verificar a estabilidade térmica das bioglicerinas misturadas com a água obtiveram-se curvas TGA/DTG com taxa de aquecimento de $10{ }^{\circ} \mathrm{C} \mathrm{min}{ }^{-1}$ para a bioglicerina lote $\mathrm{C}$, acrescida de 10, 20, 30 e 50\% de água como pode ser visualizado pela Figura 2.

A análise da Figura 2 revelou que a adição de água à glicerina provocou uma diminuição da temperatura de início de degradação (Ti) com variação de até $6,84 \%$, da temperatura máxima de degradação (Tmáx) com variação de até $11,52 \%$ e percentual de perda de massa com variação de até $3,51 \%$, quando comparado com a bioglicerina lote $\mathrm{C}$ sem adição de água (Tabela 2). A maior alteração foi observada quando se adicionou $50 \%$ de água à bioglicerina, com um máximo na curva da derivada em relação à temperatura em aproximadamente $188^{\circ} \mathrm{C}$ e um resíduo de $9,49 \%$ em torno de $300^{\circ} \mathrm{C}$. No entanto, vale ressaltar que da mesma forma que nos testes da bioglicerina sem adição de água, neste caso também houve perda de massa devido à vaporização do glicerol iniciando-se em torno de $120^{\circ} \mathrm{C}$. Não se observou nenhum evento que indicasse perda de moléculas de água, o que sugere que estas moléculas estejam fortemente ligadas. Assim, percebe-se que o sistema bioglicerina:água em qualquer proporção é altamente estável em atmosfera inerte.

Adicionalmente, a miscibilidade da mistura glicerina:água pode ser alterada com o aumento da temperatura provocando uma diminuição da sua estabilidade devido a separação de fases. Assim, resolveu-se verificar em qual temperatura (Cloud Point Temperature, 

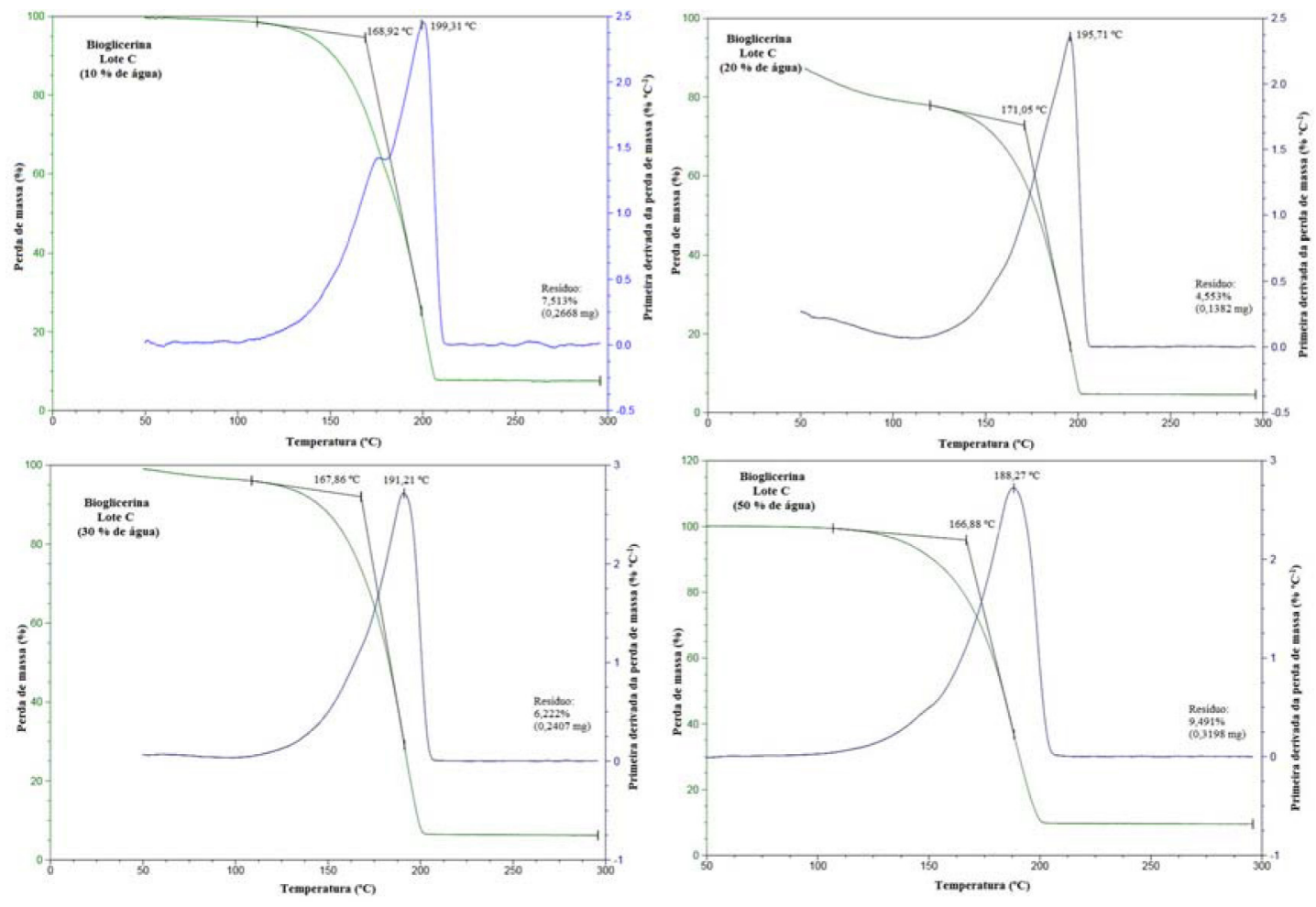

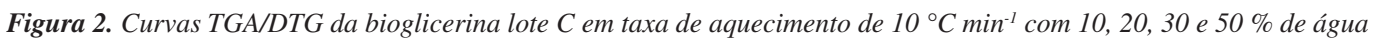

CPT) ocorre essa separação. O resultado do teste mostrou que as bioglicerinas do lote $\mathrm{D}$ sem adição de água e com adição de 10, 30 e $50 \%$, dos lotes A, B, C e E com adição de $50 \%$ de água e padrão dietilenoglicol com adição de $50 \%$ de água necessitaram de temperaturas superiores a $130{ }^{\circ} \mathrm{C}$ para iniciar a separação de fases. Bland ${ }^{35}$ observou uma relação inversa entre a concentração de glicerol e a CPT. Semelhante aos resultados obtidos na análise termogravimétrica, as bioglicerinas avaliadas nas condições experimentais deste trabalho apresentam elevada CPT e, portanto, mais uma vez, constata-se sua alta estabilidade térmica em atmosfera inerte.

Com o intuito de complementar o estudo da estabilidade dessas amostras, realizou-se uma análise em atmosfera oxidante utilizando temperatura constante de $93{ }^{\circ} \mathrm{C}$ (temperatura aproximada para envelhecimento de fluidos de perfuração). Esta medida foi feita utilizando-se um Rancimat e o gráfico da Figura 3 mostra o período de indução (início do aparecimento de produtos de oxidação) para as bioglicerinas avaliadas.

De acordo com Rivaldi, ${ }^{19}$ a presença de ácidos graxos e outras

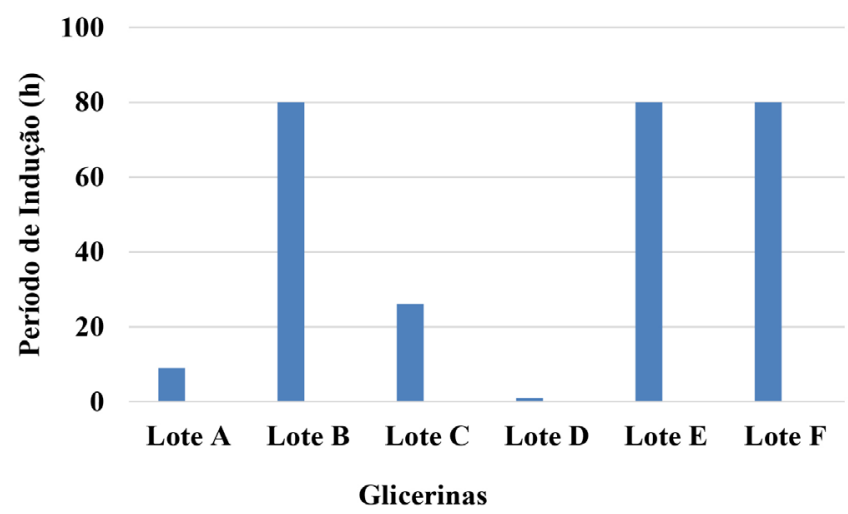

Figura 3. Período de indução (horas) obtido em atmosfera oxidante por meio de um Rancimat para as bioglicerinas avaliadas impurezas podem estar associados ao glicerol e, se esses ácidos forem saturados, a amostra terá maior estabilidade à oxidação se comparado a uma glicerina que contém ácidos graxos insaturados em sua composição. ${ }^{36}$ Os ésteres que também podem estar presentes na bioglicerina na forma de impurezas oxidam facilmente, sendo bastante instáveis em condições utilizadas durante a perfuração de um poço de petróleo. Neste contexto, observa-se pela Figura 3 que as bioglicerinas com maiores porcentagens de sebo (lotes B e E) possuem alta estabilidade em atmosfera oxidante com período de indução acima de 80 horas, semelhante a bioglicerina purificada (lote F) e contrário as bioglicerinas com maiores teores de soja (lotes A e C) e a bioglicerina proveniente de óleo residual (lote D), a qual foi a menos estável nas condições avaliadas.

Esta análise normalmente é utilizada para se determinar a estabilidade oxidativa do biodiesel segundo a norma EN 14112, cujo período de indução tem que ser de no mínimo $6 \mathrm{~h}$ para que o biodiesel seja considerado estável a temperatura de $110^{\circ} \mathrm{C}$. Como não existe uma norma técnica estabelecida para determinar o valor mínimo do período de indução para que uma glicerina seja considerada estável em atmosfera oxidante a temperatura de $93{ }^{\circ} \mathrm{C}$ como proposto neste trabalho, resolveu-se considerar também o mínimo de $6 \mathrm{~h}$ para que a mesma seja considerada estável. Assim, a glicerina lote A, cujo período de indução foi em torno de $10 \mathrm{~h}$, pode ser considerada, a priori, como adequada para ser utilizada como base para formulação de fluidos de perfuração levando em conta somente esta análise. Por outro lado, a bioglicerina $\mathrm{D}$ seria descartada para este fim, visto que apresentou um período de indução próximo de zero, sendo, portanto, instável em atmosfera oxidante à temperatura de $93^{\circ} \mathrm{C}$.

De maneira geral, as análises de estabilidade térmica e oxidativa foram importantes para mostrar que as bioglicerinas avaliadas, com exceção da bioglicerina lote $\mathrm{D}$, cujo período de indução foi próximo de zero, apresentam boa estabilidade térmica e podem ser utilizadas como base para formulação de fluidos de perfuração sem risco de decomposição, visto que esta estabilidade é fundamental para a manutenção das propriedades do fluido aquoso base glicerina. 


\section{Análise de reologia}

O perfil reológico, que é o comportamento da viscosidade em função da taxa de cisalhamento, ${ }^{37}$ é de fundamental importância para caracterização de fluidos de perfuração, visto que altos valores de viscosidade podem comprometer várias propriedades, como o bombeamento do fluido do tanque de armazenamento para a coluna de perfuração e possíveis erosões nas paredes do poço que podem comprometer a estabilidade da perfuração. Determinam-se também os valores de gel inicial $\left(G_{i}\right)$ e gel final $\left(G_{f}\right)$, os quais estão relacionados com a capacidade do fluido de sustentar os cascalhos gerados durante o processo de perfuração do poço quando a operação de perfuração é interrompida, evitando assim sua decantação e possível prisão da coluna. Essa característica que permite aos fluidos adquirir um estado semi-rígido quando em repouso e fluidez quando em movimento é conhecida como tixotropia.

Assim como a análise do perfil reológico é importante para a caracterização do fluido pronto, considera-se que esta análise também seja importante para a base que será utilizada na formulação deste fluido, visto que essas propriedades reológicas são ajustadas com a adição de aditivos específicos como viscosificantes, gelificantes, adensantes, dentre outros. Ou seja, se a base já apresentar um perfil semelhante ao fluido desejado, não será necessária a utilização de aditivos para modificar as propriedades desta base. Por outro lado, se a base apresentar um perfil muito diferente do fluido desejado, a utilização de aditivos será necessária até o completo ajuste de tais propriedades. Assim, sugere-se neste trabalho que a análise da reologia seja um dos principais parâmetros para avaliar se uma determinada matéria-prima (como a glicerina) poderá ser ou não utilizada como base em formulações de fluidos de perfuração para poços de petróleo e gás.

A Figura 4 (A e B) apresenta os resultados obtidos da reologia a $120{ }^{\circ} \mathrm{F}\left(49^{\circ} \mathrm{C}\right)$ das glicerinas para o limite de escoamento (LE), viscosidade plástica (VP) e os utilizados para avaliar a capacidade em formar géis, após envelhecimento em forno rotativo a $200{ }^{\circ} \mathrm{F}$ $\left(93^{\circ} \mathrm{C}\right)$ durante 16 horas.

Quando se trata de um fluido de perfuração com aditivos segundo normas API RP 13B-1, é recomendável que o fluido apresente valores de L3 (reologia a baixas taxas de cisalhamento) elevados para garantir uma boa capacidade de transporte e sustentação dos cascalhos no interior do poço. ${ }^{38}$ É importante ressaltar que durante a perfuração do poço ocorre a incorporação de sólidos ao fluido e, consequentemente, as propriedades reológicas são alteradas para valores mais elevados. Devido a isso, normalmente inicia-se a perfuração de uma dada fase com baixos valores de L600 e L3 (fluido inicial) e com o progresso da perfuração acompanha-se o contínuo aumento dessas propriedades. ${ }^{38}$ Por outro lado, valores de gel inicial $\left(\mathrm{G}_{\mathrm{i}}\right)$ e final $\left(\mathrm{G}_{\mathrm{f}}\right)$ não podem ser nem muito elevados, nem muito abaixo dos valores estipulados pela norma API RP 13B-132 (3-12 lbf / $100 \mathrm{ft}^{-2}$ para G $\mathrm{G}_{\mathrm{i}}$ e 8-20 lbf / $100 \mathrm{ft}^{-2}$ para $G_{f}$ ). $S e G_{i}$ e $G_{f}$ forem muito elevados, ao reiniciar-se a perfuração após uma parada, uma alta viscosidade exigiria grande esforço mecânico, e se forem muito baixo podem ocasionar o entupimento do poço devido a não sustentação dos cascalhos. ${ }^{39}$

Observa-se por meio da análise reológica (Figura 4A) que todas as bases avaliadas (sem utilização de aditivos) apresentaram valores de $\mathrm{L} 3$ e $\mathrm{G}_{\mathrm{f}}$ abaixo de 2 após o envelhecimento em forno rotativo, com exceção das bases do lote $\mathrm{C}$ (bioglicerina $70 \%$ soja), cujo valor de $G_{f}$ foi de $12 \mathrm{lbf} / 100 \mathrm{ft}^{-2}$. O valor de $G_{f}$ para a glicerina lote $C$ é o único que está dentro do estipulado pela norma API RP 13B-1 ${ }^{32}$ para fluidos completos. Assim, considera-se que esta matéria-prima pode ser utilizada como base na formulação de fluidos de perfuração aquoso sem a necessidade, a priori, da utilização de aditivos com capacidade gelificante. As demais bioglicerinas (lotes A, B, D, E, F,
$=\mathbf{L 3}=\mathbf{G f}$

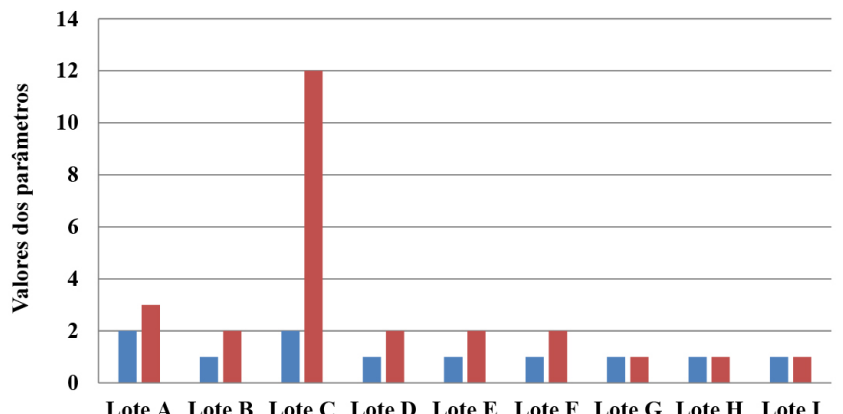

Glicerinas

B

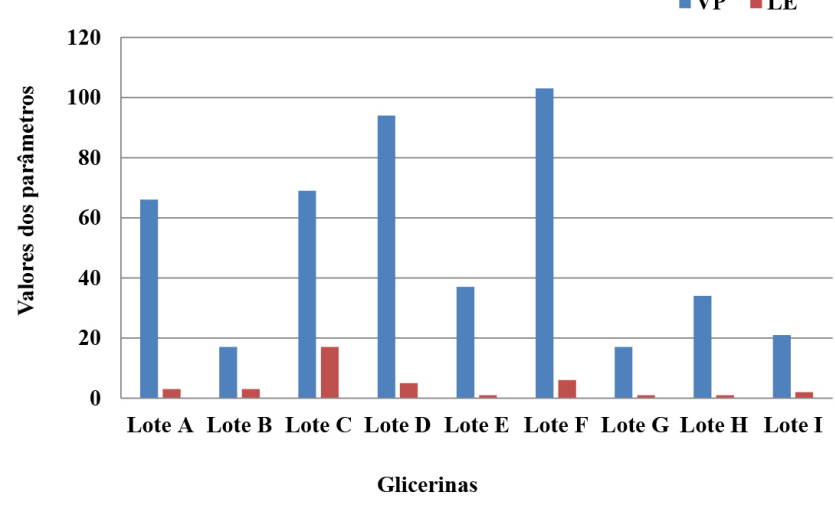

Figura 4. Representação gráfica comparativa das propriedades reológicas para as bioglicerinas após o envelhecimento: A) viscosidade L3 (3 rpm) e força gel final $G_{f}\left(\right.$ lbf $\left.\left.100 f^{-2}\right) ; B\right)$ viscosidade plásitca VP $(c P)$ e limite de Escoamento LE (lbf $\left.100 \mathrm{ft}^{-2}\right)$

G, H e I) necessitam de aditivos específicos para ajustar as propriedades $L 3$ e $G_{f}$.

O gráfico da Figura 4B mostra um comparativo entre VP e LE para as bioglicerinas após o envelhecimento em forno rotativo. A VP é considerada como a medida da resistência interna para fluir um fluido, como resultado da interação dos sólidos que estão presentes em um fluido de perfuração. ${ }^{27}$ Valores de VP abaixo de $10 \mathrm{cP}$ não são adequados para fluidos de perfuração e é indicativo de que o LE está muito alto e isso pode levar a um estado de floculação para os sólidos presentes. Por outro lado, valores de VP muito acima de 10 cP (alta viscosidade) pode gerar sobrecarga para o sistema de bombeamento de fluido. ${ }^{40}$ Observa-se pela Figura $4 \mathrm{~B}$ que todas as bases apresentaram valores de LE abaixo de $20 \mathrm{lbf} / 100 \mathrm{ft}^{-2}$ com menores valores para as bases lotes E, G e H, e VP com valores entre 17 e 103 cP com maiores valores para as bases lotes $\mathrm{F}$ e $\mathrm{D}$, respectivamente. De forma geral, nenhuma das bioglicerinas avaliadas apresentou VP em acordo com o mínimo estipulado pela norma, devendo, portanto, utilizar aditivos adequados para o ajuste desta propriedade.

Estes resultados mostram que as bioglicerinas avaliadas constituem bases com propriedades reológicas diferentes que necessitam ou não da adição de aditivos para ajuste de certas propriedades, mas que podem ser testadas na formulação de fluidos de perfuração aquoso, com a perspectiva de que os fluidos desenvolvidos também tenham propriedades diferentes. Essas diferenças no comportamento reológico podem ser atribuídas, por exemplo, às diferenças na porcentagem de glicerol, MONG, água e sal das amostras estudadas (Tabela 1), como verificado nos lotes A, G, H e I, todas $100 \%$ soja e mesmo grau de pureza, cujos valores de VP são bem diferentes. 
O lote A apresentou VP maior que $60 \mathrm{cP}$, enquanto os lotes $\mathrm{G}, \mathrm{H} \mathrm{e}$ I apresentaram VP menor que $40 \mathrm{cP}$. Pode também ser atribuídas às diferentes matérias-primas utilizadas na sua obtenção ou a presença de metanol, voláteis e outros resíduos que alteram a viscosidade tais como observado para as bioglicerinas lotes A (soja, VP > 60 cP) e B (sebo, VP $<20 \mathrm{cP}$ ), e suas misturas, lotes $\mathrm{C}$ (70:30 soja:sebo, VP $75 \mathrm{cP})$ e E (60:40 sebo:soja, $\mathrm{VP}<40 \mathrm{cP})$ de mesmo grau de pureza.

\section{Salinidade}

A salinidade é uma propriedade química que mede a concentração de sais como $\mathrm{NaCl}, \mathrm{KCl}$ e $\mathrm{CaCl}_{2}$, os quais são utilizados como aditivos nas formulações de fluidos base aquosa e determinada pelo teor de cloretos presentes no volume obtido nos testes de filtrados API ou HTHP. 32

A concentração de cloretos nas bioglicerinas está relacionada, principalmente, com o ponto de saturação de sal neste novo tipo de base, cuja importância está relacionada, por exemplo, na não dissolução de sais em perfuração de formações salinas como no pré-sal brasileiro e, até mesmo, para formulação inicial dos fluidos de perfuração onde não pode ocorrer precipitação de sais. Além disso, um custo menor de sal seria necessário para a obtenção de uma determinada resistividade elétrica, visto que estas bioglicerinas já possuem sal na sua composição.

Os valores típicos de salinidade usados em fluidos de perfuração apresentam um larga faixa que pode ser acima de 15.000 ppm e abaixo de 400.000 ppm, dependendo do cenário e tipo de fluido base. No entanto, do ponto de vista da legislação ambiental, em alguns cenários de perfuração sensíveis, como aquíferos argilosos de água doce, é proibido o uso de fluidos salgados inibidos acima de $250 \mathrm{ppm}$ de cloretos. ${ }^{41}$ A Tabela 3 apresenta os resultados obtidos das análises para determinação do teor de cloreto.

Tabela 3. Teor de cloreto $\left(\mathrm{Cl}^{-}\right)$obtido pelo método de Mohr para as glicerinas avaliadas

\begin{tabular}{ccc}
\hline Lote & Matéria-prima & Teor de $\mathrm{Cl}^{-}\left(\mathrm{mg} \mathrm{L}^{-1}\right)$ \\
\hline A & $100 \%$ soja & 25000 \\
B & $100 \%$ sebo & 27000 \\
C & $70: 30$ (soja: sebo) & 31000 \\
D & Óleo residual & $\mathrm{nd}^{\mathrm{a}}$ \\
E & $60: 40$ (sebo:soja) & 35000 \\
F & Glicerina Purificada & 500 \\
G & $100 \%$ soja & 51500 \\
H & $100 \%$ soja & 32500 \\
I & $100 \%$ soja & 49000 \\
\hline
\end{tabular}

and = Não determinado

Todas as bioglicerinas apresentaram teor de cloreto bastante variáveis e isto também levará às diferenças nos pontos de saturação de $\mathrm{NaCl}$ quando os fluidos forem preparados com estas bases. Assim, é importante conhecer o ponto de saturação de $\mathrm{NaCl}$ para cada base que for utilizada nas formulações de fluidos aquosos de modo que apresentem propriedades adequadas e estáveis a tal salinidade.

Vale ressaltar que a presença de sal nessas bases diminuiria o custo do fluido, visto que uma menor quantidade de $\mathrm{NaCl}$ seria necessário para obter uma resistividade elétrica compatível com o cenário a ser perfurado. Nos resultados mostrados na Tabela 3 pode-se verificar que a glicerina do lote $\mathrm{F}$ demandará maior quantidade de $\mathrm{NaCl}$ para obter a mesma resistividade quando comparado aos demais lotes, além disso, o seu uso como base implicaria em maior custo quando comparada às demais bioglicerinas que não passaram por processos de purificação. Por outro lado, somente esta bioglicerina poderia ser utilizada como base para formular fluidos aquosos com baixos valores de cloretos exigido para cenários de perfuração sensíveis. As demais bases, por sua vez, estariam aptas para serem usadas em todos os outros tipos de cenários.

Comparando os resultados obtidos de cloretos $\left(\mathrm{mg} \mathrm{L}^{-1}\right)$ usando o método de Mohr, Tabela 3, e os resultados fornecidos pelos laudos, Tabela 1, observou-se valores diferentes, provavelmente devido às variações entre os lotes do mesmo produto.

\section{Teste de inchamento de argila (folhelho)}

Aproximadamente $75 \%$ das formações perfuradas são constituídas de folhelhos aos quais associam-se $90 \%$ dos problemas de instabilidade de poço, ${ }^{42}$ principalmente quando estão relacionados à entrada de água nas entrecamadas dos folhelhos, resultando em um inchamento da rocha. ${ }^{43}$ Para prevenir ou minimizar estes problemas de instabilidade normalmente utilizam-se inibidores de inchamento de argila na formulação do fluido. Assim, o teste de inchamento de argilas (folhelhos) é um parâmetro importante que deve ser realizado para avaliar a possível interação que possa ocorrer entre a base e o folhelho que será perfurado. Quanto menor for essa interação, melhor será a base e menor serão os problemas relacionados à instabilidade do poço.

O ensaio de deformação linear avalia a ocorrência de interações diretas entre a base ou o fluido de perfuração e a argila nos primeiros momentos de contato entre eles. Este ensaio mede o grau de inchamento que pode ser tolerado antes da desintegração da argila, assim como avalia a eficiência da base utilizada na formulação de um fluido de perfuração ou do próprio fluido. As medidas de deformação são realizadas através de um transdutor automático-digital, o qual permite a leitura da deformação, e a partir destes valores é calculada a porcentagem de deformação linear, dividindo-se o valor de deformação pela altura original da amostra.

A Figura 5 mostra as curvas de porcentagem de inchamento de argila versus tempo obtidas a partir das análises de inchamento de argila com a água industrial, com a mistura 50:50 água:glicerina (lotes E, C, H, I e glicerina purificada lote F. Também foram testados os inibidores catiônicos $\mathrm{KCl}$ e uma solução livre de cloreto.

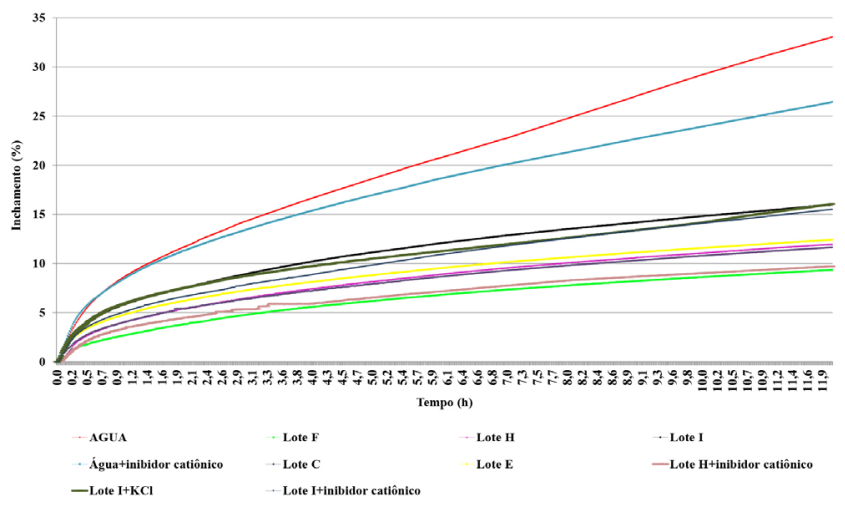

Figura 5. Representação gráfica comparativa das curvas de porcentagem de inchamento de argila versus tempo (horas) para água e algumas glicerinas testadas com e sem inibidores

A análise da Figura 5 mostrou que as bioglicerinas analisadas com e sem inibidores apresentaram porcentagens de inchamento menores que $15,5 \%$, abaixo dos percentuais de inchamento da água com e sem inibidor, cujos valores alcançaram máximos de 26 e $33 \%$, 
respectivamente. Isto mostra que o uso dessas bioglicerinas como base para fluidos de perfuração, mesmo na ausência de inibidores de inchamento de argila, podem minimizar os problemas relativos à instabilidade de poços especialmente quando se perfura zonas com folhelhos.

A glicerina do lote $\mathrm{F}$, a qual apresenta uma maior quantidade de glicerol (99,7 - 100\%) (Tabela 1), apresentou maior eficiência na inibição de inchamento de argila, com um valor máximo em torno de $9 \%$, seguida pelas bioglicerinas dos lotes $\mathrm{C}$, E e H que possuem em torno de $84 \%$ de glicerol e apresentaram em torno de $12 \%$ de inchamento. Já a bioglicerina do lote I, a qual possui menor teor de glicerol $(72 \%)$ com e sem inibidor de inchamento apresentou comportamento semelhante para este teste, com porcentagens máximas entre 15 e $16 \%$. Este resultado mostra que quanto maior quantidade de glicerol presente na bioglicerina usada, maior poderá ser sua eficiência para inibir o inchamento de argilas, ou seja, menor será a interação da bioglicerina com o folhelho e, portanto, menor serão os problemas relacionados à instabilidade do poço.

Vale ressaltar que quanto maior a quantidade de glicerol, maior será o custo da glicerina. Neste caso, é imprescindível que se verifique a relação custo-benefício para utilização desta base mais purificada.

O uso dos inibidores catiônicos mostraram uma melhora na eficiência de inchamento de argila, uma vez que quando ocorre troca dos íons $\mathrm{Na}^{+}$presentes nas entrecamadas dos folhelhos pelos íons $\mathrm{K}^{+}$do inibidor catiônico, a estrutura da argila fica mais estável, dificultando a delaminação das partículas..$^{43}$ Assim, por exemplo, a bioglicerina lote $\mathrm{H}$ com adição da solução catiônica livre de cloreto apresentou uma porcentagem de inchamento semelhante ao da glicerina purificada (lote F), com máximo em torno de $10 \%$. Os dois inibidores utilizados, $\mathrm{KCl}$ e a solução catiônica livre de cloreto, apresentaram praticamente a mesma eficiência quando foram usados com a bioglicerina do lote I, podendo a escolha ser determinada pelo valor do produto ou pelas restrições ambientais.

Os inibidores inorgânicos, como o $\mathrm{KCl}$ ou $\mathrm{NaCl}$, possuem baixo custo, mas podem causar danos ambientais e, por isso, são normalmente substituídos por sais isentos de cloreto, mesmo estes sendo de custos mais elevados.

A Figura 6 mostra as imagens da face interna dos corpos de prova de argila bentonita utilizados nos testes de inchamento. É visível como a água invade todo corpo de prova e ocorre inchamento da amostra. Já para as bases glicerinas o centro do corpo de prova permanece seco e intacto. Observa-se, ainda, que o raio de invasão é menor quando se usa a glicerina purificada, corroborando o que foi observado pelo gráfico da Figura 5.

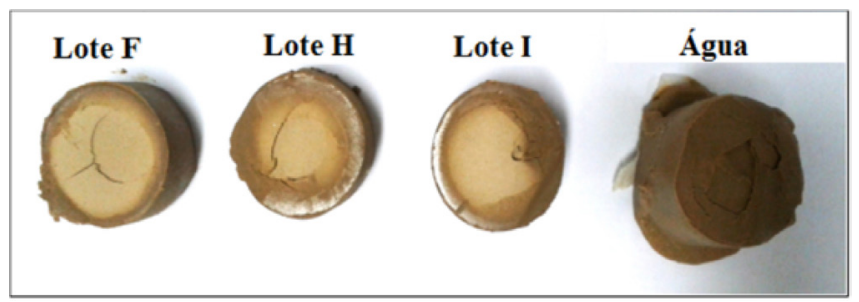

Figura 6. Imagens ilustrativas dos corpos de prova de argila bentonita após teste de inchamento evidenciando as interações com a água e algumas glicerinas avaliadas

\section{Medida de tensão interfacial}

Na perfuração de uma formação rochosa, uma das funções do fluido de perfuração é prevenir dano à formação que está sendo perfurada, reduzindo a passagem de fluido (filtrado) para dentro da formação, através de um reboco que é formado com as partículas sólidas presentes no fluido. Quando o reboco não é eficiente e este filtrado invade a formação rochosa, se ele possuir uma alta tensão interfacial, pode ocorrer dano por efeito capilar especialmente em campos de gás de baixa permeabilidade, levando a uma diminuição da produtividade do poço.

A Figura 7 apresenta os resultados obtidos das análises de tensão interfacial, à temperatura de $22^{\circ} \mathrm{C}$, para as bioglicerinas dos lotes $\mathrm{B}$, C, E e para a glicerina purificada lote F. Também foi realizado com água industrial e com soluções aquosas dessas glicerinas (50:50, 60:40 e 70:30).

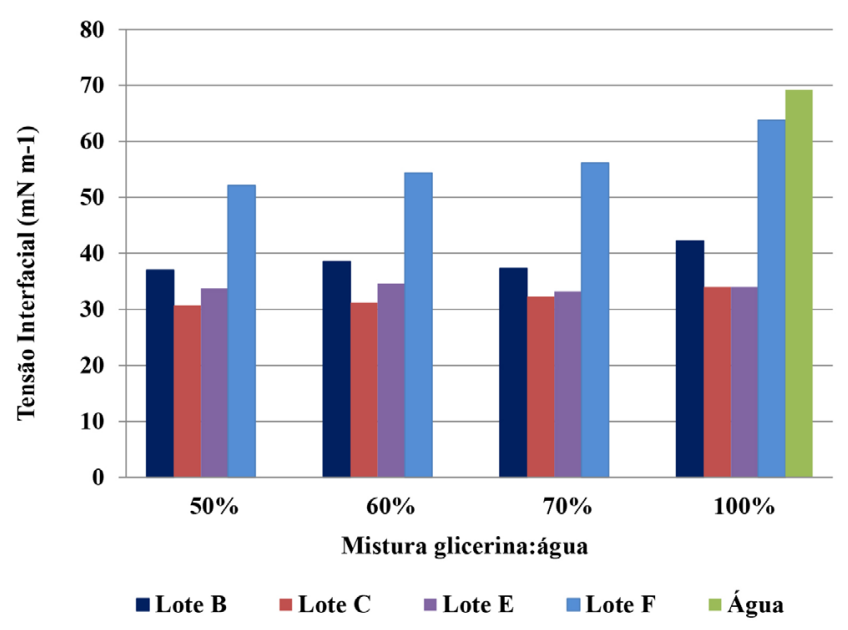

Figura 7. Gráfico representativo da tensão interfacial $\left(\mathrm{mNm}^{-1}\right)$ para diferentes proporções da mistura água:glicerina dos lotes B, C, E e F

Observou-se que as bioglicerinas que possuem menores teores de glicerol (lotes B, C e E) e presença de impurezas inerentes ao processo de obtenção, tais como MONG, apresentaram menores valores de tensão interfacial (30-40 $\left.\mathrm{mN} \mathrm{m}^{-1}\right)$ quando comparadas com a água $\left(69 \mathrm{mN} \mathrm{m}^{1}\right)$ e com a glicerina purificada (lote F) $\left(52-64 \mathrm{mN} \mathrm{m}^{1}\right)$, independentemente da proporção bioglicerina:água utilizada. Neste caso, ressalta-se que a presença das impurezas nas bioglicerinas podem ter provocado um efeito surfactante que levou à diminuição do valor da tensão interfacial. Considerando-se somente esta análise, verifica-se que essas bioglicerinas podem ser utilizadas, sem prévio tratamento, como bases para formular fluidos aquosos que poderiam ser aplicados em cenários de reservatórios de gás de baixa permeabilidade, onde é necessário ter filtrados com valores de tensão interfacial menor que o da água, causando menor dano por efeito capilar quando invadirem a zona perfurada. Além disso, o uso destas bioglicerinas como base para fluidos reduziria os gastos com produtos específicos e de alto custo, como surfactantes especiais que normalmente são utilizados em fluidos nos quais a água é a base..$^{44-47}$

\section{CONCLUSÃO}

As glicerinas avaliadas, com exceção do lote D, apresentaram boa estabilidade térmica e oxidativa e nenhuma separação de fases mesmo em elevadas temperaturas, dando um indicativo da sua aplicação como base para fluidos de perfuração, uma vez que estes passam por processos de envelhecimento em torno de 99 a $124^{\circ} \mathrm{C}(200$ a 250 $\left.{ }^{\circ} \mathrm{F}\right)$ e precisam ser estáveis. Além disso, os testes de inchamento de argila mostraram sua pouca interação com a argila.

Em adição, as análises de reologia mostraram que essa matéria-prima apresenta propriedades reológicas diferentes, mas que podem ser testadas como base na formulação de fluidos de perfuração com aditivos específicos para ajuste dessas propriedades segundo as normas vigentes. 
Assim, considera-se que este resíduo proveniente da produção do biodiesel representa uma alternativa real para aplicação em fluidos de perfuração aquoso em substituição a outras bases orgânicas, apresentando vantagem relativa aos aspectos ambientais, sociais e econômicos, podendo, inclusive, ser considerada como um importante fator de viabilização do desenvolvimento sustentável.

Por fim, esse artigo contribui para implementar um protocolo analítico que pode ser adotado para avaliar e qualificar bases para formulação de fluidos de perfuração, visto que não existem normas técnicas específicas com este intuito.

\section{MATERIAL SUPLEMENTAR}

Figuras contendo os espectros de $\mathrm{RMN}{ }^{1} \mathrm{H}$, os cromatogramas obtidos por CG/DIC e CG/EMIT e curvas TGA/DTG de algumas bioglicerinas analisadas neste trabalho estão disponíveis em http:// quimicanova.sbq.org.br, na forma de arquivo PDF, com acesso livre.

\section{AGRADECIMENTOS}

Os autores agradecem ao CENPES/PETROBRAS (Projeto P\&D $n^{\circ}$ 2014/00149-7) pelo suporte financeiro, à FAPERJ pela bolsa concedida e ao Prof. R. B. dos Santos da UFES pela aquisição dos espectros de $\mathrm{RMN}{ }^{1} \mathrm{H}$.

\section{REFERÊNCIAS}

1. Thomas, J. E.; Fundamentos de Engenharia de Petróleo, $2^{\text {nd }}$ ed., Interciência: Rio de Janeiro, 2001.

2. Khodja, M.; Khodja-Saber, M.; Canselier, J. P.; Cohaut, N.; Bergaya, F. Em Drilling Fluid Technology: Performances and Environmental Considerations, Products and Services; Fuerstner, I., ed.; InTech: Rijeka, 2010. DOI: 10.5772/10393.

3. Machado, J. C. V.; Oliveira, M. M.; Publicação interna, Petrobras, 1986.

4. Darley, H. C. H.; Gray, G. R.; Composition and properties of drilling and completion fluids, $5^{\mathrm{th}}$ ed., Gulf Publishing Company: Houston, 1988.

5. Friedheim, J. E.; Shinnie, J. R.; IADC/SPE 21941 Drilling Conference , Amsterdam, Holanda, 1991.

6. Bourgoyne Jr, A. T.; Millheim, K. K.; Chenevert, M. E.; Young Jr, F. S.; Applied Drilling Engineering, $2^{\text {nd }}$ ed., Richardson: Texas, 1991.

7. Simpson, J. P.; Walker, T. O.; Jiang, G. Z.; IADC/SPE Drilling Conference, Dallas, Texas, 1994.

8. Friedheim, J.; Toups, B.; van Oort, E.; AADE Annual Technology Forum, Houston, Texas, 1999.

9. oung, S. Y.; Maas, T.; National Drilling Technical Conference, Houston, Texas, 2001

10. Patel, A.; Stmatakis, E.; Friedheim, J. E.; Davis, E.; National Drilling Technical Conference, Houston, Texas, 2001.

11. Schlemmer, R.; Friedheim, J. E.; Growcock, F. B.; Bloys, J. B.; Hedley, J. A.; Polnaszec, S. C.; IADC/SPE Drilling Conference, Dallas, Texas, 2002.

12. Friedheim, J. E.; Conn, H. L.; IADC/SPE Drilling Conference, Dallas, Texas, 1996.

13. http://www.ibama.gov.br/licenciamento, acessada em Janeiro de 2017.

14. Mota, C. J. A.; da Silva, C. X. A.; Gonçalves, V. L. C.; Quim. Nova 2009, 32, 639 .

15. Kirk, R. E.; Othmer, D. F.; Encyclopedia of Chemical Technology, $4^{\text {th }}$ ed., Wiley: New York, 2001.

16. Ooi, T. L., Young, K. C., Hazimah, A. H., Dzulkefly, K., Wan-Yunus, W. M. Z.; J. Oleo Sci. 2004, 53.

17. Appleby, D. B. Em Manual do Biodiesel; Knothe, G., Gerpen, J. V., Krahl, J., Ramos, L. P., eds.; Edgard Blücher, 2006, p.295-309.

18. Thompson, J. C.; He, B. B.; Applied engineering in agriculture 2006, $22,261$.
19. Rivaldi, J. D.; Sarrouh, B. F.; Fiorilo, R.; Silva, S. S.; Biotecnologia, Ciência e desenvolvimento 2007, 37, 44.

20. Vasconcelos, Y.; Revista Pesquisa Fapesp 2012, 196, 58.

21. Borges, S. M. S.; Almeida, P. M. M.; Quintella, C. M.; Resumos da 30 Reunião anual da sociedade Brasileira de Química, Águas de Lindóia, Brasil, 2007.

22. Souza, N. A. F.; Lins, M. C. M.; Batista, R. F.; Gomes, R. T.; Resumos da X Jornada de Ensino, Pesquisa e Extensão da UFRPE, Recife, Brasil, 2010.

23. Yaakoub, M. C.; Rodrigues Jr., J. A.; Lachter, E. R.; Nascimento, R. S.; Resumos da $32^{a}$ Reunião Anual da Sociedade Brasileira de Química, Fortaleza, Brasil, 2009.

24. Candler, J. P. E.; Friedheim, J.; $13^{\text {th }}$ International Petroleum Environmental Conference, San Antonio, Texas, 2006.

25. Cunha, R. R.; Da Cruz, G. F.; Corrêa, C. C.; Vaz Jr., A. S.; Lomba, R. F. T.; Silva, C.; Anais do $7^{\circ}$ Congresso Brasileiro de P \& D em Petróleo e Gás, Aracaju, Brasil, 2013.

26. Cunha, R. R.; Trabalho de Conclusão de Curso, Universidade Estadual do Norte Fluminense Darcy Ribeiro, Brasil, 2015.

27. Curbelo, F. D. S.; Garnica, A. I. C.; Melo, M. A. F.; Melo, D. M. A.; PI0908661-7A2 2009

28. Pinheiro, R. S.; César, A. S.; Batalha, M. O.; Resumos do XXX Encontro Nacional de Engenharia de Produção, São Carlos, Brasil, 2010.

29. http://www.portaldainovacao.org/pi/detalhe/179, acessada em Janeiro de 2017.

30. Pormerleau, D. G.; US pat 2009/0143254 2009.

31. Marbun, B. T. H.; Aristya, R.; Corina, A. N.; Hutapea, P. A.; American Journal of Oil and Chemical Technologies 2013, 1, 1.

32. API RP 13B-1; Recommended Practice for Field Testing Water-based Drilling Fluids, $4^{\text {th }}$ ed., Washington, DC, 2009.

33. Lôbo, I. P.; Ferreira, S. L. C.; Da Cruz, R. S.; Quim. Nova 2009, 32, 1596.

34. Castelló, M. L.; Dweck, J.; Aranda, D. A. G.; J. Therm. Anal. Calorim. 2009, 97, 627 .

35. Bland, R. G.; SPE International Conference on Health, Safety and Environment, Jakarta, Indonesia, 1994.

36. Canakci, M.; Bioresour. Technol. 2007, 98, 183.

37. Machado, J. C. V.; Reologia e Escoamento dos Fluidos: Ênfase na Indústria do Petróleo, $1^{\mathrm{a}}$ ed., Interciência: Rio de Janeiro, 2002.

38. Moreira, G. P.; Costa, M.; Araújo, R. G. M.; Girão, J. H. S.; Garcia, R. B.; Anais do $4^{\circ}$ Congresso Brasileiro de P \& D em Petróleo e Gás, Campinas, Brasil, 2007.

39. Barros, A. O.; Lachter, E. R.; Nascimento, R. S. V. N.; Anais do $4^{\circ}$ Congresso Brasileiro de P \& D em Petróleo e Gás, Campinas, Brasil, 2007.

40. Nascimento, R. C. A. M.; Amorim, L. V.; Santana, L. N. L.; Cerâmica 2010, 56, 179 .

41. Vaqueiro, C. L. R.; Dissertação de Mestrado, Universidade de São Paulo, Brasil, 2006.

42. Osisanya, S. O.; Chenevert, M. E.; J. Pet. Technol. 1996, 35, 53.

43. Nascimento, R. C. A. M.; Vieira, T. M.; Amorim, L. V.; Lira, H. L.; Revista Eletrônica de Materiais e Processos 2009, 4.2, 12.

44. Elkewidy, T. I.; SPE Kuwait International Petroleum Conference and Exhibition, Kuwait City, Kuwait, 2012.

45. Ogugue, C. E.; Rathan, M. P.; Shah, S. N.; SPE Oil and Gas India Conference and Exhibition, Mumbai, Índia, 2010.

46. Lakatos, I. J.; Bodi, T.; Lakatos-Szabo, J.; Szentes, G.; SPE International Symposium and Exhibiton on Formation Damage Control, Lafayette, USA, 2010.

47. Nasr-El-Din, H. A.; Al-Mohammed, A. M.; Al-Fuwaures, O. A.; AlAamri, A.; SPE Annual Technical Conference and Exhibition, Anaheim, California, 2007. 